\title{
Evolution of Emission Species in an Aero-Engine Turbine Stator
}

\author{
André A. V. Perpignan ${ }^{1, *(\mathbb{D})}$, Stella Grazia Tomasello ${ }^{2}$ (i) and Arvind Gangoli Rao $1, *$ (i) \\ 1 Faculty of Aerospace Engineering, Delft University of Technology, Kluyverweg 1, 2629 HS Delft, \\ The Netherlands \\ 2 Department of Industrial Engineering, University of Florence, Via di S. Marta 3, 50139 Firenze, Italy; \\ stella.tomasello@stud.unifi.it \\ * Correspondence: andreperpignan@gmail.com (A.A.V.P.); A.GangoliRao@tudelft.nl (A.G.R.)
}

Citation: Perpignan, A.A.V.;

Tomasello, S.G.; Rao, A.G. Evolution of Emission Species in an Aero-Engine Turbine Stator. Aerospace 2021, 8, 11. https://doi.org/10.3390/ aerospace 8010011

Received: 24 November 2020 Accepted: 23 December 2020 Published: 4 January 2021

Publisher's Note: MDPI stays neutral with regard to jurisdictional clai$\mathrm{ms}$ in published maps and institutional affiliations.

Copyright: $@ 2021$ by the authors. Licensee MDPI, Basel, Switzerland. This article is an open access article distributed under the terms and conditions of the Creative Commons Attribution (CC BY) license (https:// creativecommons.org/licenses/by/ $4.0 /)$.

\begin{abstract}
Future energy and transport scenarios will still rely on gas turbines for energy conversion and propulsion. Gas turbines will play a major role in energy transition and therefore gas turbine performance should be improved, and their pollutant emissions decreased. Consequently, designers must have accurate performance and emission prediction tools. Usually, pollutant emission prediction is limited to the combustion chamber as the composition at its outlet is considered to be "chemically frozen". However, this assumption is not necessarily valid, especially with the increasing turbine inlet temperatures and operating pressures that benefit engine performance. In this work, Computational Fluid Dynamics (CFD) and Chemical Reactor Network (CRN) simulations were performed to analyse the progress of $\mathrm{NO}_{\mathrm{x}}$ and $\mathrm{CO}$ species through the high-pressure turbine stator. Simulations considering turbulence-chemistry interaction were performed and compared with the finite-rate chemistry approach. The results show that progression of some relevant reactions continues to take place within the turbine stator. For an estimated cruise condition, both $\mathrm{NO}$ and $\mathrm{CO}$ concentrations are predicted to increase along the stator, while for the take-off condition, $\mathrm{NO}$ increases and $\mathrm{CO}$ decreases within the stator vanes. Reaction rates and concentrations are correlated with the flow structure for the cruise condition, especially in the near-wall flow field and the blade wakes. However, at the higher operating pressure and temperature encountered during take-off, reactions seem to be dependent on the residence time rather than on the flow structures. The inclusion of turbulencechemistry interaction significantly changes the results, while heat transfer on the blade walls is shown to have minor effects.
\end{abstract}

Keywords: $\mathrm{NO}_{\mathrm{x}}$ emissions; high pressure turbine; chemical reactor networks; eddy dissipation concept

\section{Introduction}

The importance of reducing greenhouse gases and pollutant emissions has been pushing the transition to renewable energy. In most of the forecasted future scenarios, the role of gas turbines will continue to be important. In energy generation, gas turbines are expected to utilise hydrogen or synthetic fuels, utilising the excess energy production of the inherently intermittent solar and wind sources [1-3]. Additionally, biofuels could directly be used in gas turbines [4]. In aviation, gas turbines will play an important role and will continue to lead the "energy mix", as fully electric alternatives are not expected to be feasible in the near future [5]. Therefore, developments in the combustion technology of gas turbines are required to make these engines sustainable.

One of the most important aspects to be improved in gas turbines is the emission of pollutant species. the reduction of $\mathrm{NO}_{x}$ has especially received attention not only because of its detrimental local effects, but also because of its potential to significantly affect the climate [6]. The analysis of new solutions and strategies to reduce emissions requires accurate predictions. As pollutant emissions are lowered, the required precision and level of detail within the modelling approaches need to be increased to allow for sound design decisions. Added to that, the increasing operating temperatures and pressures 
attained by gas turbines (beneficial to their cycle efficiency) cause the chemistry in the sections subsequent to the combustion chamber to be relevant from an emissions point of view. Therefore, the evolution of chemical species in the stator of the high-pressure turbine, downstream of the combustion chamber might be necessary for accurate emission prediction and management.

\subsection{Background}

Previously developed models to predict emissions vary in their approaches with respect to complexity, fidelity, and variables taken into account. The majority of models have employed the assumption that the pollutant emissions at the combustion chamber outlet remain constant and, therefore, can be considered as the output of the gas turbine [7-10]. In such models, only the chemistry inside the combustor is considered. It is worth noting that this is the standard practice for emissions prediction, and many recent works rely on combustor correlations for calculating $\mathrm{NO}_{x}$ emissions, as the work of Thoma et al. [11].

However, some modelling works were dedicated to including the rest of the engine in order to study the composition of exhaust gases. The vast majority of past works was related to the evolution of sulphur species and aerosol precursors within the engine. The work of Lukachko et al. [12] is an example of such studies. In a rather comprehensive study, the authors presented results for both one and two-dimensional approaches. The 1D model considered both turbines (the high-pressure turbine, HPT, and the low-pressure turbine, LPT), as well as the nozzle section. The authors compared different sets of initial composition (calculated utilising a chemical equilibrium assumption or non-equilibrium). For the considered conditions, $\mathrm{NO}$ and $\mathrm{NO}_{2}$ were predicted to decrease. It is worth pointing out that the investigated turbine inlet temperatures (TIT) ranged from 1459 to $1820 \mathrm{~K}$ at approximately 15 bars. These values are relatively low when compared to the operating conditions of current aeroengines at take-off conditions.

When utilising the 2D model of a stator blade row, $\mathrm{NO}$ was shown to increase while $\mathrm{NO}_{2}$ decreased [12]. An important conclusion of this work is the relatively poor comparison between the 1D and 2D approaches. The study was, however, performed with a rather simple chemical reaction mechanism with respect to $\mathrm{CO}$ and $\mathrm{NO}_{\mathrm{x}}$ chemistry, as the authors were mainly interested in sulphur species.

Also focusing on aerosol precursors, the work of Starik et al. [13] presented a Chemical Reactor Network (CRN) model to represent the whole gas turbine engine downstream of the compressor section, including all turbine sections and the exhaust nozzle. The focus was on calculating the concentrations of ionized species along the engine hot section downstream of the combustor. The most important conclusion of the work for the present paper is that $\mathrm{NO}_{x}$ related species still had significant variations after exiting the combustion chamber. When displaying the results for NO concentration, they pointed to an increase in concentration from the combustor exit to the nozzle exhaust for an RB211 under cruise condition (TIT equal to $1540 \mathrm{~K}$ and the turbine inlet pressure of $11 \mathrm{bar}$ ). However, for a JT9D-7A engine (TIT = $1200 \mathrm{~K}$ and pressure of $7.7 \mathrm{bar}$ ), the NO concentration decreased. The concentrations of $\mathrm{CO}$ were shown to decrease after the combustion chamber for both cases. Once again, these conditions exhibit lower pressures and temperatures with respect to those of modern aeroengines.

The work of Moniruzzman and Yu [14] was also focused on modelling an aircraft engine, the CFM56-2-C1, which was tested in NASA's APEX (Aircraft Particle Emissions eXperiment) program [15]. The authors simulated the engine at the idle condition, as outlet values of emissions were available. Utilising a 0D batch-reactor model, the authors utilised gas parcels to represent the unmixed nature of the flow at the combustor inlet. As a conclusion, $\mathrm{NO}_{\mathrm{x}}$ species were predicted to change by as much as a factor of 2 when comparing the combustor and the nozzle outlets, which is a relatively high difference. At the investigated condition, $\mathrm{NO}$ was shown to decrease after the combustion chamber with an increase in $\mathrm{NO}_{2}$. The concentration of $\mathrm{CO}$ decreased in the post-combustor region. 
Again, with a focus on aerosol precursors and particulates, Bisson et al. [16] utilised a CRN model to investigate diverse flight conditions: idle, take-off, climb and approach. Having analysed the species related to the particulate formation and sulphur species in more detail, the authors broadly summarised that $\mathrm{NO}_{\mathrm{x}}$ and $\mathrm{CO}$ concentrations were mostly constant or had a slight decrease downstream of the combustion chamber dilution zone, under all the visited conditions. The presented plots on the evolution of the involved species show that $\mathrm{NO}_{2}$ increased across the HPT for all conditions, while the decrease in $\mathrm{CO}$ along the HPT was pronounced for the take-off and climb conditions (TIT of approximately $1500 \mathrm{~K})$.

Recently, a work exploring 3D modelling of an HPT stage has been presented [17]. The authors focused on the effect of chemical reactions on temperature, pressure and velocity. Additionally, they also reported results on the evolution of $\mathrm{NO}_{\mathrm{x}}$ and $\mathrm{SO}_{\mathrm{x}}$ related species. By utilising a finite rate chemistry approach with no turbulence-chemistry interaction model, the authors concluded that temperatures drop substantially less across the turbine stage when considering chemical reactions (a difference of approximately $200 \mathrm{~K}$ ), while pressures are maintained practically the same. Such a result is rather surprising and is further discussed in Section 4 of the present work. Moreover, $\mathrm{NO}$ was shown by the authors to decrease while $\mathrm{NO}_{2}$ increased at the chosen condition (TIT $=1341 \mathrm{~K}$ and turbine inlet total pressure of $31.13 \mathrm{bar}$ ).

From analysing previous works on the subject, it becomes clear that there is a lack of understanding regarding the evolution of $\mathrm{CO}$ and $\mathrm{NO}_{x}$ downstream the combustion chamber. Previous publications had contrasting results with each other, which cannot be directly attributed to operating conditions or modelling. Additionally, it is still unclear what type of modelling is required to predict such progression and what regulates the trend of the species. The aforementioned studies did not include any turbulence-chemistry interaction modelling, while the considered operating conditions had relatively low TIT and pressure compared to modern and future gas turbines. These shortcomings are addressed in the present work.

\subsection{Motivation}

Reducing emissions of minor pollutant species for future gas turbines requires innovation and computational tools that can accurately predict trends and emission values. The progression of chemical species in the regions after the combustion chamber is more relevant with the strict emission levels and ever-increasing OPR and TIT, especially at the HPT where the high temperatures and pressures occur.

The relevance is even higher when considering alternative engine architectures, as the one investigated within the AHEAD project [18]. The proposed dual-combustor configuration (Figure 1) has the HPT between the engine's main combustor (fuelled by LNG or $\mathrm{LH}_{2}$ ) and the Inter-Turbine Burner (ITB). Such a dual-combustor configuration was chosen for a multi-fuel blended wing body concept, which used a cryogenic fuel (LNG or $\left.\mathrm{LH}_{2}\right)$ and liquid fuel (biofuel or kerosene). Therefore, the progression of species along the HPT is also important as it directly affects the chemistry within the ITB. The ITB engine configuration is not necessarily applicable only for a multi-fuel aircraft as it has shown to have a better off-design performance characteristic when compared to a normal turbofan engine [19]. The ITB has shown to have a substantial potential to reduce $\mathrm{NO}_{\mathrm{x}}$ emissions [20,21].

In this paper, the evolution of pollutant emissions within the HPT stator is investigated. The operating conditions were chosen based on the design of the dual-combustor engine concept. The effect of different modelling approaches (CFD and Chemical Reactor Network) is compared, as well as the use of different chemical reaction mechanisms, the inclusion of turbulence-chemistry interaction, engine operating conditions and heat loss due to the cooling of the blades. The objective of the current research is to further understand how $\mathrm{CO}$ and $\mathrm{NO}_{\mathrm{x}}$ evolve along the HPT stator and what parameters affect the development of these minor species. The practical application of such understanding is the development of computational tools able to accurately predict the production of pollutant species by 
gas turbine engines. These computational tools may vary in complexity and approach. Nevertheless, the inclusion of the phenomena that take place in the HPT is key to the accuracy of any computational tool, as the following sections show.

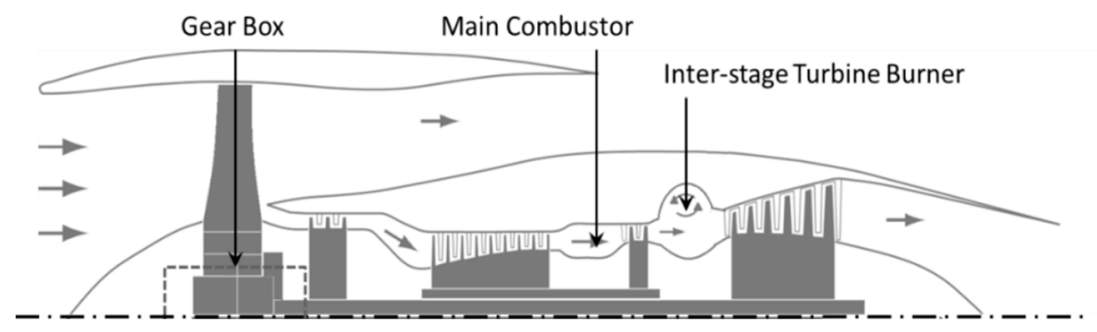

Figure 1. Dual-combustor engine concept developed on the AHEAD project [22].

\section{Test Case Geometry}

The investigation of the chemistry within the turbine stator requires the use of a representative geometry that has experimental data on some aspects of the flow field to allow for the validation of the CFD models. One of the turbine sections developed in the NASA's Energy Efficient Engine program with General Electric was chosen. The HPT geometry and performance data for the E3 program are available in a report [23].

The two-stage turbine was designed to have a pressure ratio of 4.933 at the defined top of climb condition (usually the most challenging condition apart from the take-off). The first stage stator herein simulated is composed of 46 vanes. The vanes were designed to achieve Mach $0.815,0.878$ and 0.910 at the outlet for tip, mean radius and hub, respectively. The vanes had an axial width of $33.78 \mathrm{~mm}$ at the mean radius $(345.76 \mathrm{~mm}$ ). The geometry description can be found in Table 1.

Table 1. Stator vane geometry as described by Timko.

\begin{tabular}{cccc}
\hline Dimension & Hub & Mean & Tip \\
\hline Radius (mm) & 325.755 & 345.760 & 365.760 \\
Axial width (mm) & 33.76 & 33.78 & 33.83 \\
Trailing edge thickness (mm) & 0.965 & 0.965 & 0.965 \\
Uncovered turning (degrees) & 9.2 & 8.4 & 8.7 \\
Trailing edge wedge angle (degrees) & 10.2 & 9.2 & 9.0 \\
\hline
\end{tabular}

The experimental campaigns collected data on pressures and temperatures at some stations of the HPT. Moreover, this test case has been simulated in previous works [24,25]. The previous experiences allowed for an easier definition of the CFD setup required to successfully reproduce the stator flow field.

\section{Numerical Modelling Setup and Validation}

\subsection{Computational Fluid Dynamics}

Before looking at the chemical kinetics inside the HPT, it is important to model the flow field and make sure that it is in agreement with the experimental observations. For this reason, non-reactive flow simulations were performed and validated. Simulations were performed utilising the RANS equations along with the $k-\omega$ SST turbulence model. Total pressure and temperature were imposed at the inlet, while static pressure was imposed at the outlet. Second-order discretization was employed to every transported variable. The ANSYS Fluent ${ }^{\circledR}$ solver was utilised for all CFD simulations.

The computational mesh refinement was determined based on the Grid Convergence Index (GCI) method, described by Celik et al. [26], having the value of the overall nozzle efficiency at the outlet as the observed variable (Equation (1)). The experimental value of the stator efficiency was used for the evaluation. The chosen fully hexahedral mesh 
(Figure 2) was composed by 2.04 million elements, while the GCI method was employed utilising a coarser mesh (860 thousand elements) and a finer mesh (3.6 million elements).

$$
\eta_{V}=\frac{1-\left(p_{S, 1} / p_{T, 1}\right)^{\frac{\gamma-1}{\gamma}}}{1-\left(p_{S, 1} / p_{T, 0}\right)^{\frac{\gamma-1}{\gamma}}} .
$$

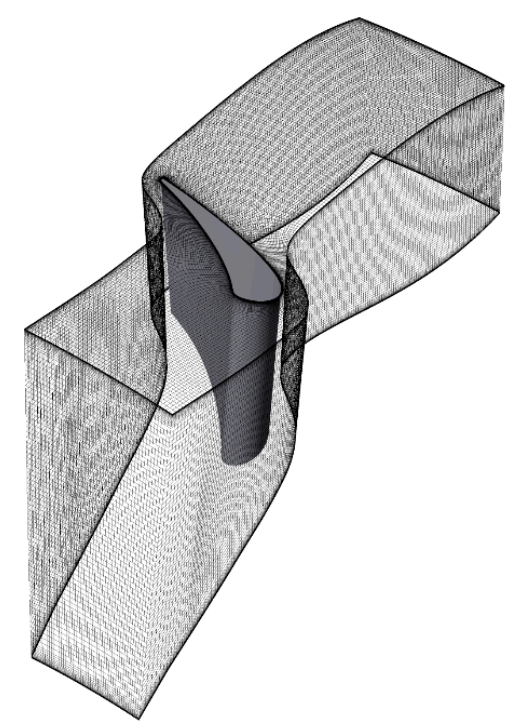

Figure 2. Fully hexahedral computational mesh employed for the CFD simulations.

The comparison between simulations results and experimental data on both isentropic Mach numbers (Figure 3) and vane efficiency show good agreement. The deviations in isentropic Mach are lower than 1\% for all points if the two outliers, one at $50 \%$ span and the other at $90 \%$ span, are excluded. Figure 4 . shows the results of $\eta_{V}$. at a plane located $10.16 \mathrm{~mm}$ away from the trailing edge of the vane. The deviation for $\eta_{V}$. is below $3 \%$ for all data points. Given this level of agreement, the fluid model was considered validated and, therefore, the reactive flow simulations were carried out utilising the same mesh, numerical settings and turbulence model. The mesh provided a $y^{+}$. of around 1 for all domain walls and a maximum $y^{+}$. of 1.5 close to the domain outlet for all the investigated conditions. Moreover, adequate boundary layer resolution was ensured for all conditions.
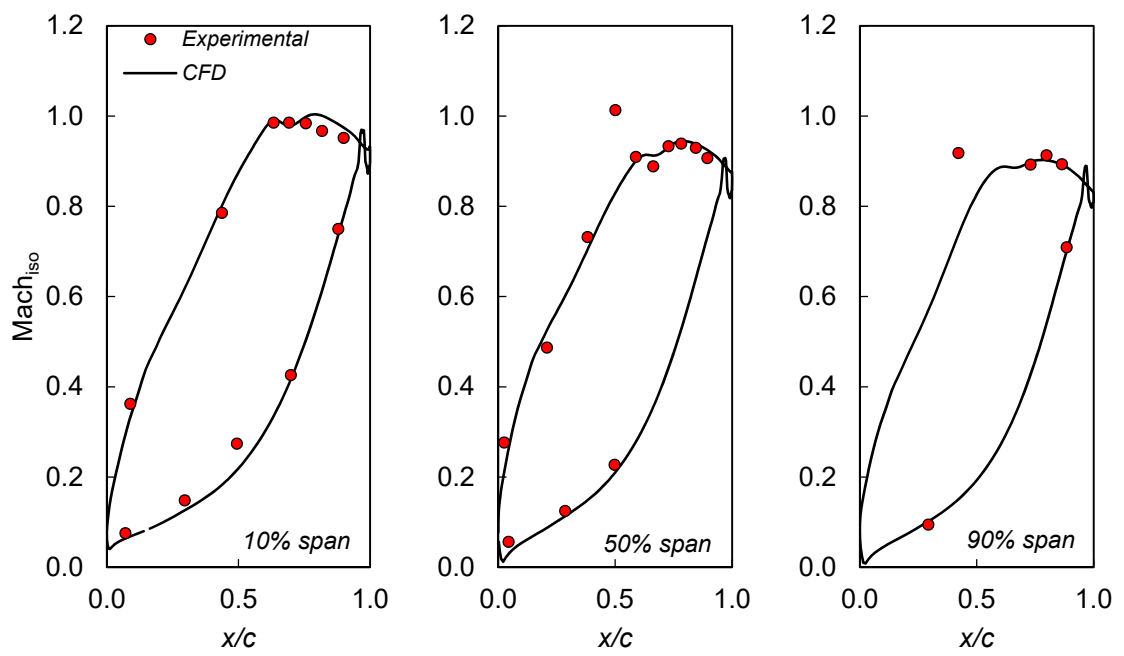

Figure 3. Comparison of isentropic Mach number at three different blade spans between experimental [23] and CFD values. 


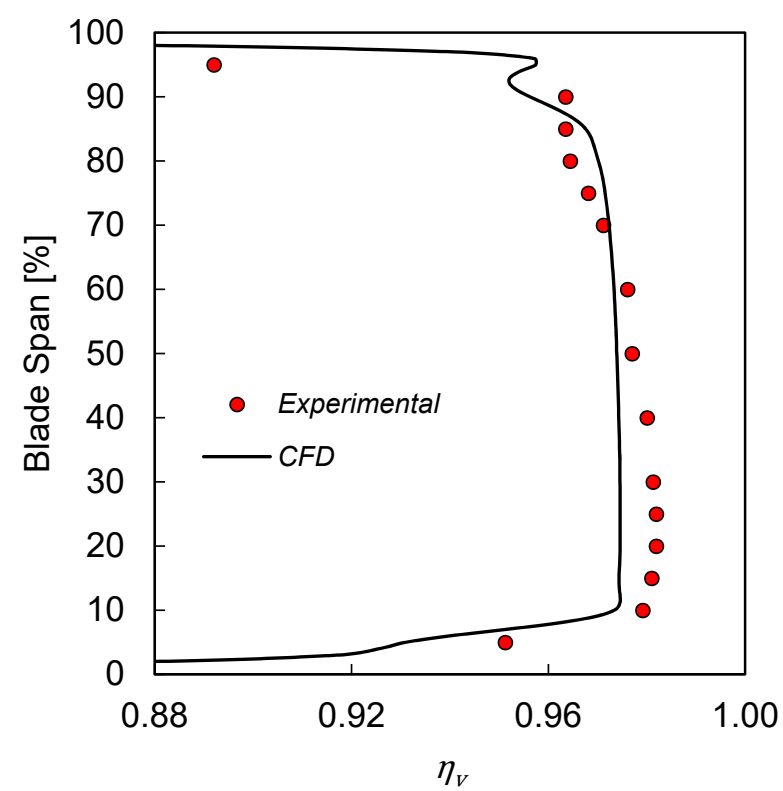

Figure 4. Comparison between experimental [23] and CFD values of vane efficiency at a plane located $10.16 \mathrm{~mm}$ downstream of the vane trailing edge.

Chemical reactions were included in the CFD simulations with two different approaches: one considering only finite-rate chemistry (FRC) without turbulence-chemistry interaction and the other using a turbulence-chemistry interaction model, namely the Eddy Dissipation Concept (EDC). This choice allows for a comparison with previous works and to assess the effect of turbulence on the reactions.

The EDC model follows the assumption that chemical reactions occur within turbulent fine scales and that reaction rates are proportional to the mass transfer between these fine scales and their surroundings. The formulation employed in this work [27] defines the fine structure time-scale $\tau^{*}$. as shown in Equation (2). This time-scale is equal to the Kolmogorov time-scale multiplied by a constant, which has a value of 0.4083 in the adopted formulation. The time-scale is utilised along the length fraction of the fine structures $\gamma_{\lambda}$, shown in Equation (3), to define the reaction rates (Equation (4)).

$$
\begin{gathered}
\tau^{*}=C_{\tau}\left(\frac{v}{\varepsilon}\right)^{1 / 2} . \\
\theta_{\lambda}=C_{\theta}\left(\frac{v \varepsilon}{k^{2}}\right)^{1 / 4} \\
\overline{R_{i}}=\frac{\bar{\rho} \gamma_{\lambda}^{2}\left(\widetilde{Y}_{i}-Y_{i}^{*}\right)}{\tau^{*}\left(1-\gamma_{\lambda}^{3}\right)} .
\end{gathered}
$$

Reaction rates are proportional to the mass transfer between the fine structures and their surroundings and are also dependent on the concentration difference of a given species between the surroundings and the fine structures $\left(\widetilde{Y}_{i}-Y_{i}^{*}\right)$. Therefore, the formulation defines the fine structure volumes, which are then treated as ideal chemical reactors.

The advantage of the model is the possibility of utilising any chemical reaction mechanism without any simplification or dimensional reduction, which is beneficial to predict minor species. Additionally, it is not bounded to any specific combustion regime. Despite being classically used in combustion simulations, the model is adequate for the flow within the turbine due to its lack of assumption regarding the reaction's regime or flame shape, unlike some of the other combustion models e.g., flamelet-based models.

The default convergence parameters from the ANSYS Fluent ${ }^{\circledR}$ chemistry solver were modified to achieve higher accuracy. The values of the species of interest are relatively 
low (in the order of a few ppm), therefore, usual convergence criteria do not provide consistent results.

Despite the theoretical ability of the EDC to accommodate any chemical reaction mechanism, mechanisms that are too large have prohibitive computational costs. Bearing that in mind, two different chemical reaction mechanisms were utilised: the $\mathrm{NO}_{\mathrm{x}}$ subset of the San Diego mechanism [28] and the $\mathrm{H}_{2} / \mathrm{CO} \mathrm{NO}_{x}$ POLIMI mechanism [29]. The former could only be utilised when $\mathrm{H}_{2}$ was used as fuel in the first combustor, as it does not contain carbon species, and it has 20 species and 40 reactions. The latter, developed for syngas combustion, has 32 species and 173 reactions, which encompass the required reactions to calculate $\mathrm{CO}$ emissions.

The initial compositions, calculated as shown in Section 3.2, were adapted to these two mechanisms, maintaining the concentrations of common species, apart from $\mathrm{N}_{2}$, which was used to ensure the mass fractions added to 1 . In order to assure that the mechanism employed to calculate the initial conditions did not affect the general outcome of CFD simulations, the same case calculated using the GRI 3.0 [30] and $\mathrm{C}_{2} \mathrm{NO}_{\mathrm{x}}$ [31] mechanisms were compared. The trends of the species of interest were the same, and only varied slightly in their initial values.

\subsection{Operating Conditions and Calculation of Initial Composition}

In order to estimate the conditions relevant to the dual-combustor engine, the cycle calculations and performance estimates performed by Yin [32] were utilised. The work provides calculations for several energy fractions between the main combustor and the ITB. The evaluation of emissions in the HPT was performed for cases in which $90 \%$ of the energy release takes place in the main combustor, while only $10 \%$ of the total energy release is in the ITB. The relatively high value was chosen due to the higher resulting temperatures in the main combustor, leading to a potentially more active and relevant pollutant evolution in the HPT. Additionally, these conditions are close to those of conventional engines.

The compositions were calculated with a CRN developed to mimic the main combustor (Figure 5). The experiments carried out within the framework of the AHEAD project [33] provided the data shown in Figure 6, with the $\mathrm{NO}_{\mathrm{x}}$ emissions of a lean-premixed modelcombustor designed to represent the main combustor. The developed CRN can replicate the emission trends reasonably well with respect to the $\mathrm{NO}_{\mathrm{x}}$ emissions measured in the experiments. It is worth noting that the available experimental data was obtained at atmospheric pressure and, therefore, the CRN was run at atmospheric pressure as well. The experiments were carried out using $\mathrm{H}_{2}$ as a fuel. More details on the experimental conditions can be found in the work of Levy et al. [33].

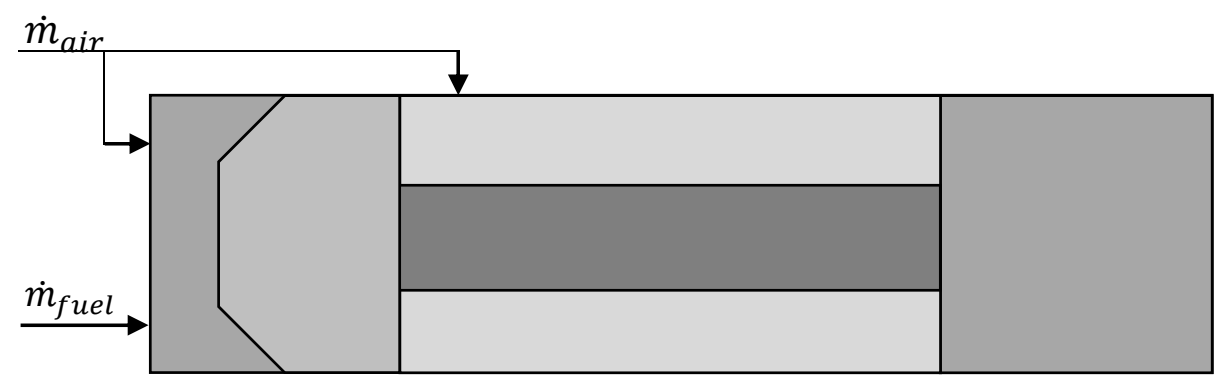

Figure 5. Schematic of the CRN employed to estimate the composition of the gases leaving the lean-premixed combustor. Each region represents a PSR. 


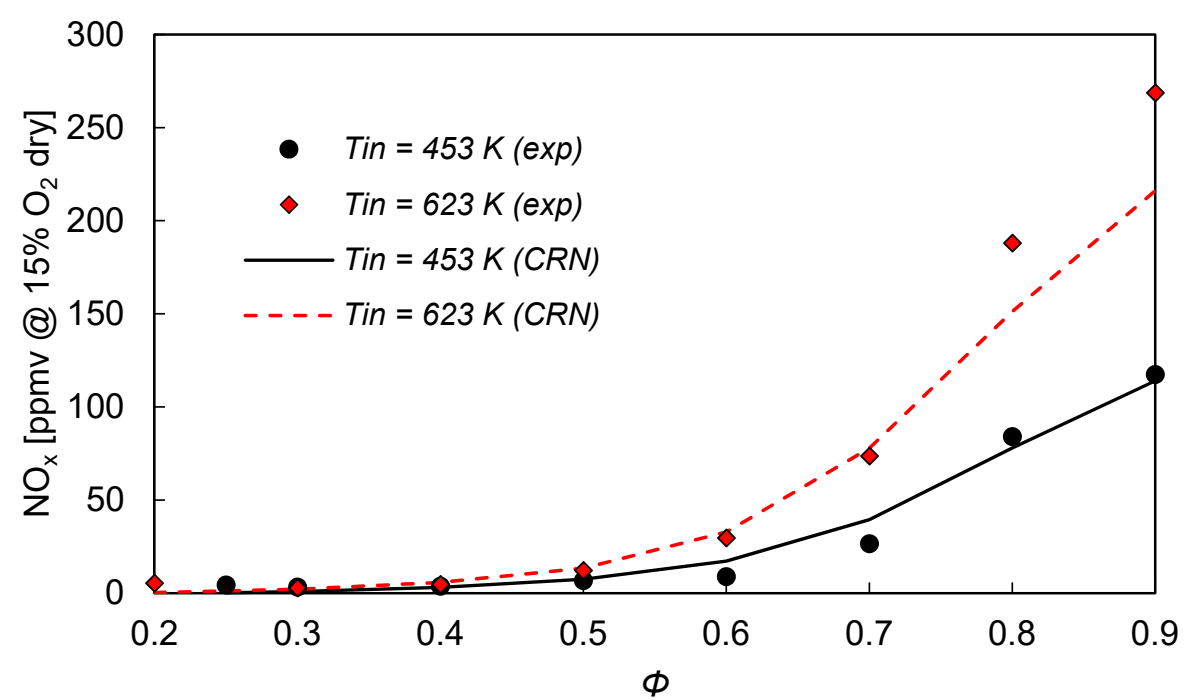

Figure 6. Comparison between experimental [33] and Chemical Reactor Network (CRN) $\mathrm{NO}_{\mathrm{x}}$ emissions results.

The imposed outlet static pressure values at the selected conditions were chosen with the aim of maintaining the flow field (evaluated in terms of Mach number) within the turbine as close as possible to its design point. The intention was to obtain flow fields representative of regular turbine operation. Table 2 displays the conditions $\mathrm{A}, \mathrm{B}, \mathrm{C}$, and $\mathrm{D}$ investigated in the present paper. Conditions $\mathrm{A}$ and $\mathrm{B}$ are the same, except for the presence of heat transfer at the blade walls in the CFD calculations. A constant wall temperature of $1400 \mathrm{~K}$ was imposed as an attempt to emulate the presence of internal blade cooling (no film-cooling). All conditions yield a residence time of below $2 \mathrm{~ms}$ in the stator section.

Table 2. Operating conditions investigated and their resulting turbine inlet conditions used as boundary conditions.

\begin{tabular}{|c|c|c|c|c|c|c|c|c|c|c|}
\hline Condition & $\begin{array}{c}\text { Main } \\
\text { Com- } \\
\text { bustor } \\
\text { Fuel }\end{array}$ & $\begin{array}{l}\text { Flight } \\
\text { Condi- } \\
\text { tion }\end{array}$ & TIT (K) & $\begin{array}{c}\text { Total } \\
\text { Pressure } \\
\text { (bar) }\end{array}$ & $\begin{array}{c}\mathrm{O}_{2} \\
\text { (\% mass) }\end{array}$ & $\begin{array}{c}\mathrm{CO}_{2} \\
\text { (\% mass) }\end{array}$ & $\begin{array}{c}\mathrm{CO} \\
(\mathrm{ppm})\end{array}$ & $\begin{array}{c}\text { NO } \\
(\mathrm{ppm})\end{array}$ & $\begin{array}{c}\mathrm{NO}_{2} \\
(\mathrm{ppm})\end{array}$ & $\begin{array}{l}\text { Blade } \\
\text { Walls }\end{array}$ \\
\hline $\mathrm{A}$ & $\mathrm{CH}_{4}$ & Take-off & 2027 & 63.37 & 11.99 & 7.31 & 44.12 & 126.45 & 1.87 & Adiabatic \\
\hline B & $\mathrm{CH}_{4}$ & Take-off & 2027 & 63.37 & 11.99 & 7.31 & 44.12 & 126.45 & 1.87 & $1400 \mathrm{~K}$ \\
\hline $\mathrm{C}$ & $\mathrm{H}_{2}$ & Cruise & 1689 & 13.93 & 16.06 & - & - & 7.81 & 0.11 & Adiabatic \\
\hline $\mathrm{D}$ & $\mathrm{CH}_{4}$ & Cruise & 1689 & 13.93 & 13.55 & 6.33 & 20.90 & 14.46 & 0.16 & Adiabatic \\
\hline
\end{tabular}

\subsection{Chemical Reactor Network}

After the CFD simulations described in Section 3.1 were performed, a CRN was developed in an attempt to simulate the turbine stator. The CFD modelling suffers from high computational costs that make it difficult to use some of the detailed chemical reaction mechanisms. The relatively low computational cost involved in the $\mathrm{CRN}$ calculation allows for the use of detailed chemical reaction mechanisms. On the other hand, CRN modelling requires a priori knowledge about the flow field or assumptions related to it. Moreover, CRNs usually neglect turbulence-chemistry interaction and details of the flow field. The purpose was to verify whether it is necessary to include such details in the modelling.

The open-source software Cantera [34] was utilised to setup and run the CRN calculations. The developed CRN was a series of PSRs, forming a Plug Flow Reactor. Tests were conducted increasing the number of PSRs until the results were found to be independent of the number of reactors. Thus, all results herein presented were obtained utilising 1000 reactors. The volume of each reactor was determined based on its axial location and imposing the cross-sectional area as shown in the profile of Figure 7. The local properties (static 
pressure, static temperature, velocity and density) calculated from CFD is presented in Figure 7 and were imposed similarly and, thereby, the CRN was used only to calculate the species. The velocity angle at a given axial location was utilised to correct the volume of the reactor in order to obtain similar residence times, as the model assumes one-dimensional flow. A similar exercise was carried out for the take-off case and the properties from the CFD simulations were subsequently utilised for the CRN analysis.
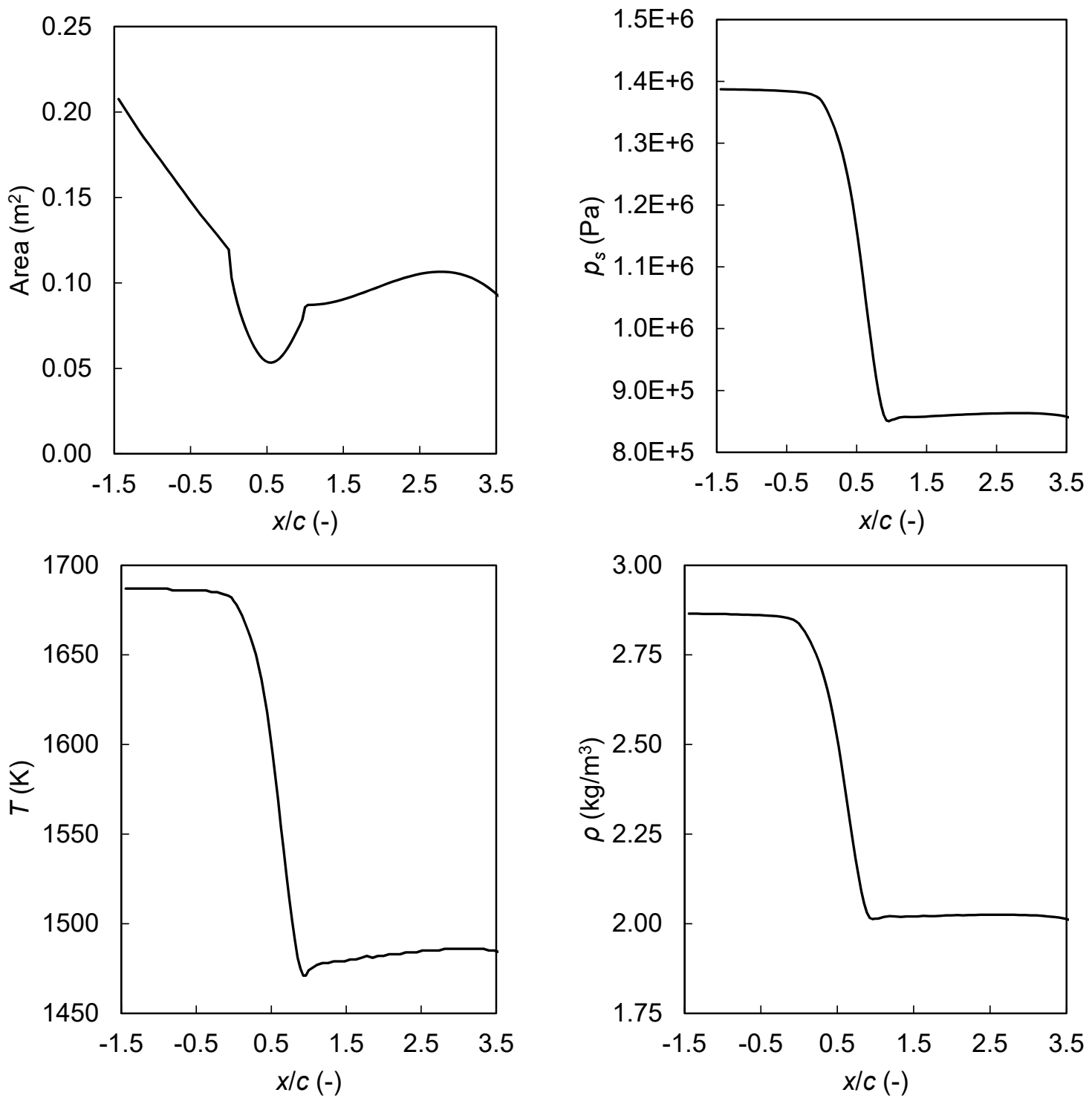

Figure 7. Profiles of cross-sectional area, static pressure, temperature and density imposed to the CRN for conditions $\mathrm{C}$ and $\mathrm{D}$ (cruise).

The CRNs were subsequently solved utilising detailed mechanisms, GRI 3.0 [30] and the C2 NOx [31], as well as with the reduced mechanisms employed in the CFD analysis. A summary of all performed simulations is presented in Table 3. 
Table 3. Simulations performed to each of the considered conditions.

\begin{tabular}{|c|c|c|c|c|}
\hline Modelling & A & B & $\mathrm{C}$ & D \\
\hline $\begin{array}{c}\text { CFD } \\
\text { San Diego NOx } \\
\text { FRC }\end{array}$ & & & $x$ & \\
\hline $\begin{array}{c}\text { CFD } \\
\text { San Diego NOx } \\
\text { EDC }\end{array}$ & & & $x$ & \\
\hline $\begin{array}{c}\text { CFD } \\
\text { POLIMI H2/CO } \\
\text { FRC }\end{array}$ & & & $X$ & $X$ \\
\hline $\begin{array}{c}\text { CFD } \\
\text { POLIMI H2/CO } \\
\text { EDC }\end{array}$ & $X$ & $X$ & $x$ & $X$ \\
\hline $\begin{array}{c}\text { CRN } \\
\text { C2 NOx }\end{array}$ & $x$ & & $x$ & $X$ \\
\hline $\begin{array}{c}\text { CRN } \\
\text { POLIMI H2/CO }\end{array}$ & $x$ & & $X$ & $X$ \\
\hline $\begin{array}{c}\text { CRN } \\
\text { San Diego NOx }\end{array}$ & $x$ & & $X$ & $X$ \\
\hline $\begin{array}{l}\text { CRN } \\
\text { GRI } 3.0\end{array}$ & $X$ & & $X$ & $X$ \\
\hline
\end{tabular}

\section{Results and Discussion}

As a first analysis, the non-reactive CFD simulations were compared to those including chemical reactions. As discussed in Section 1.1, Nguyen et al. [17] found considerable differences in the thermodynamic properties when they performed such comparison. Figure 8. displays a comparison between a non-reactive CFD simulation and an EDC simulation for condition $\mathrm{C}$ (cruise, $\mathrm{H}_{2}$ ) utilising the San Diego $\mathrm{NO}_{\mathrm{x}}$ subset. The temperature variation between the reacting and non-reacting flow simulations are all below $10 \mathrm{~K}$, much lower than reported by Nguyen et al. [17] (approximately $200 \mathrm{~K}$ ). The temperature variations seem to be related to the slight difference in density caused by the difference in composition (which occur mostly at the wake of the blades). Similar results were obtained with the POLIMI mechanism.

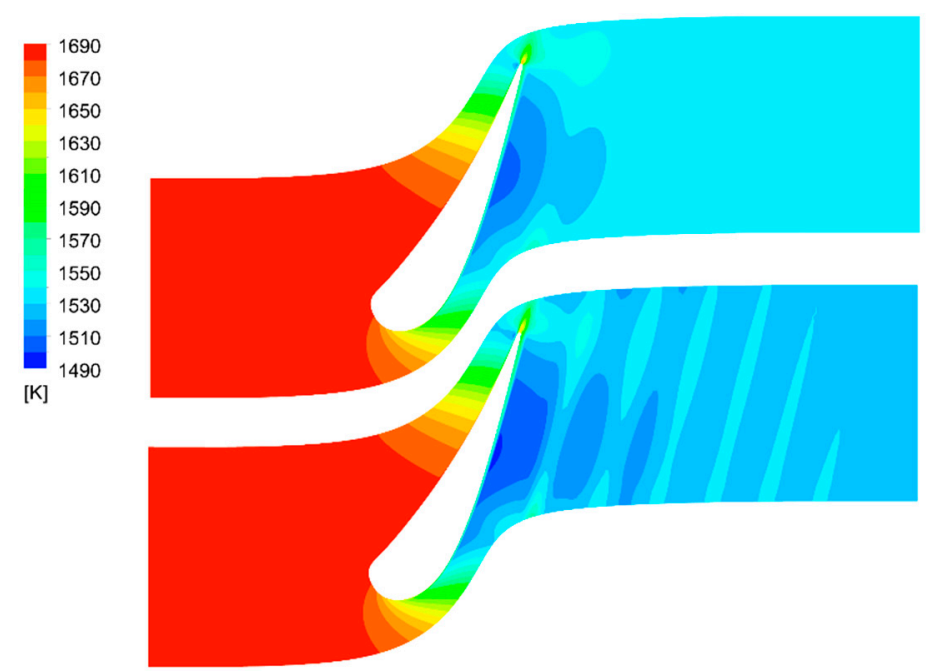

Non-Reactive

Figure 8. Temperature contours for a non-reactive simulation (above) and a reactive EDC simulation (below) for condition C. 
Comparing the cases with and without turbulence-chemistry interaction, both the FRC and EDC were applied to conditions $C$ and D. As will become clear in the discussion carried in subsequent sections, there were substantial differences in the results with the EDC, which is in principle more reliable, as the model takes turbulence-chemistry interaction into account. Therefore, the CFD simulations for conditions A and B (the most important in view of emissions regulations) were only performed utilising the EDC in order to include the turbulence-chemistry interaction.

\subsection{The $\mathrm{NO}_{x}$ Chemistry}

For conditions $\mathrm{A}$ and $\mathrm{B}$, the $\mathrm{NO}$ concentration increases along the stator according to all modelling approaches as seen in Figure 9. The predicted variations are in the order of $15 \%$ with respect to the inlet values. The comparison between CFD and CRN results is much closer for these conditions (as opposed to conditions $C$ and D). The largest variations in trend are seen in the blade region $(0<x / c<1)$ and they can be explained by the effect of the boundary layer, which is neglected in the CRN simulation. The comparison between CFD and CRN also shows that NO formation rate is slightly lower with CFD when the same chemical reaction mechanism is considered (POLIMI $\mathrm{H}_{2} / \mathrm{CO}$ ).

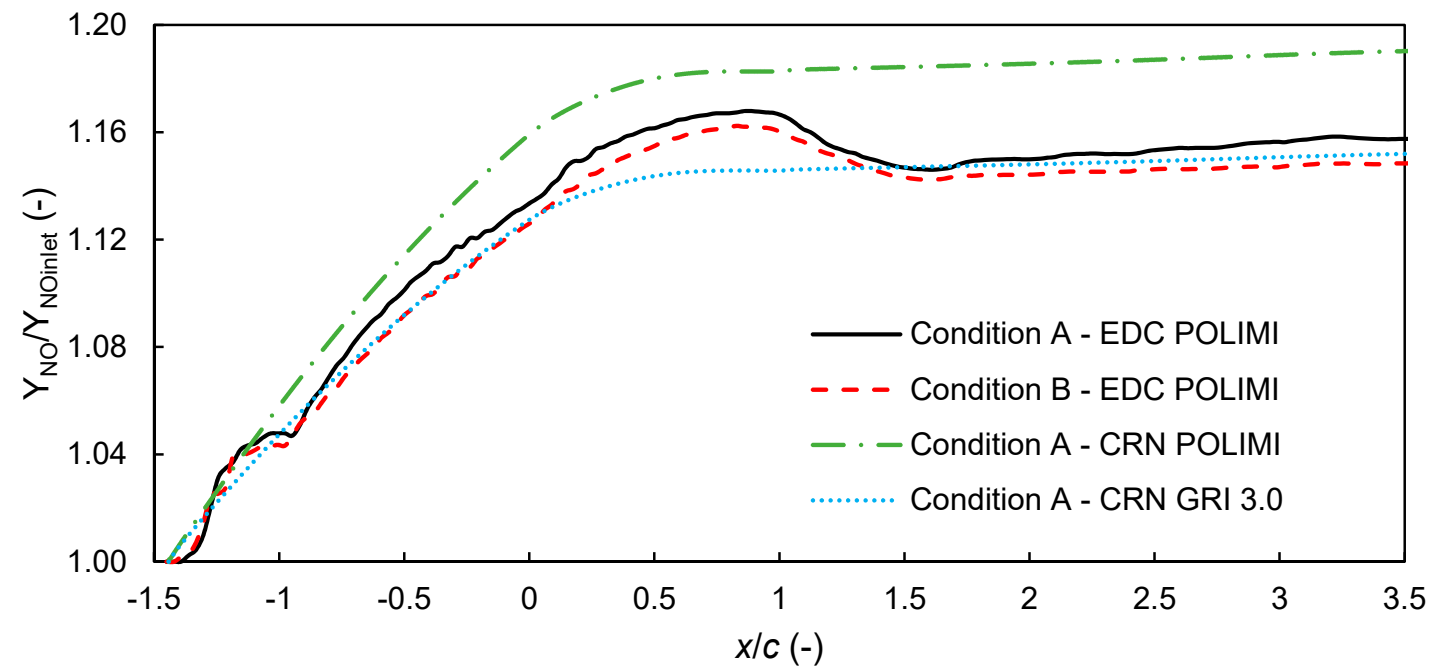

Figure 9. Mass-averaged NO mass fractions as functions of the axial location.

The comparison between conditions A and B shows that the blade cooling slightly lowers the increase in NO. The difference in the outlet values is, however, lower than $1 \%$.

The overall agreement between CFD and CRN in this case is related to the fact that the behaviour of NO is not as correlated to the flow field as in conditions $\mathrm{C}$ and $\mathrm{D}$. The stator seems to act as a mere extension of the combustion chamber. Apart from a little influence of the hub boundary layer, the behaviour of NO (shown in Figure 10) is dependent on the axial position.

Despite having higher temperatures, the relative increase in NO for conditions $\mathrm{A}$ and $B$ was lower than for conditions $C$ and $D$, shown subsequently. One of the possible reasons to explain this behaviour is the initial composition, which had a larger value of NO for conditions $\mathrm{A}$ and $\mathrm{B}$. Reaction rates are, among other variables, dependent on the species concentrations. Therefore, reaction rates may have been limited by the initial composition.

For the two cruise conditions (C and D), the CFD simulations predict a substantial increase in $\mathrm{NO}$ (Figure 11). The POLIMI $\mathrm{H}_{2} \mathrm{CO}$ mechanism predicts a higher increase in NO than the San Diego mechanism. The EDC predicts a lower increase in NO than the FRC model for both mechanisms. The overall increase in $\mathrm{NO}$ is quite high for condition $\mathrm{C}$. The lowest predicted increase (from the San Diego calculations with the EDC) is of 3.3 times the initial concentration. 


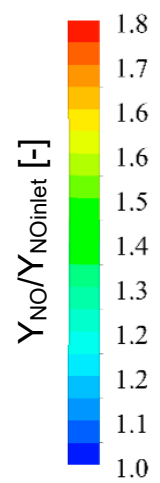

Flow Direction

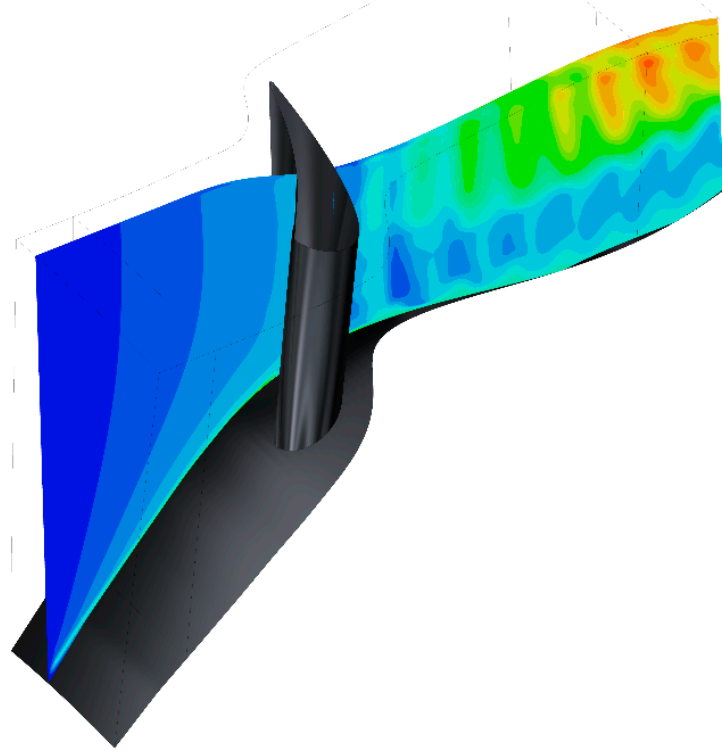

Figure 10. Local NO mass fraction, non-dimensionalised by inlet concentration for condition A on a plane, with the EDC approach and the POLIMI $\mathrm{H}_{2} / \mathrm{CO}$ mechanism.
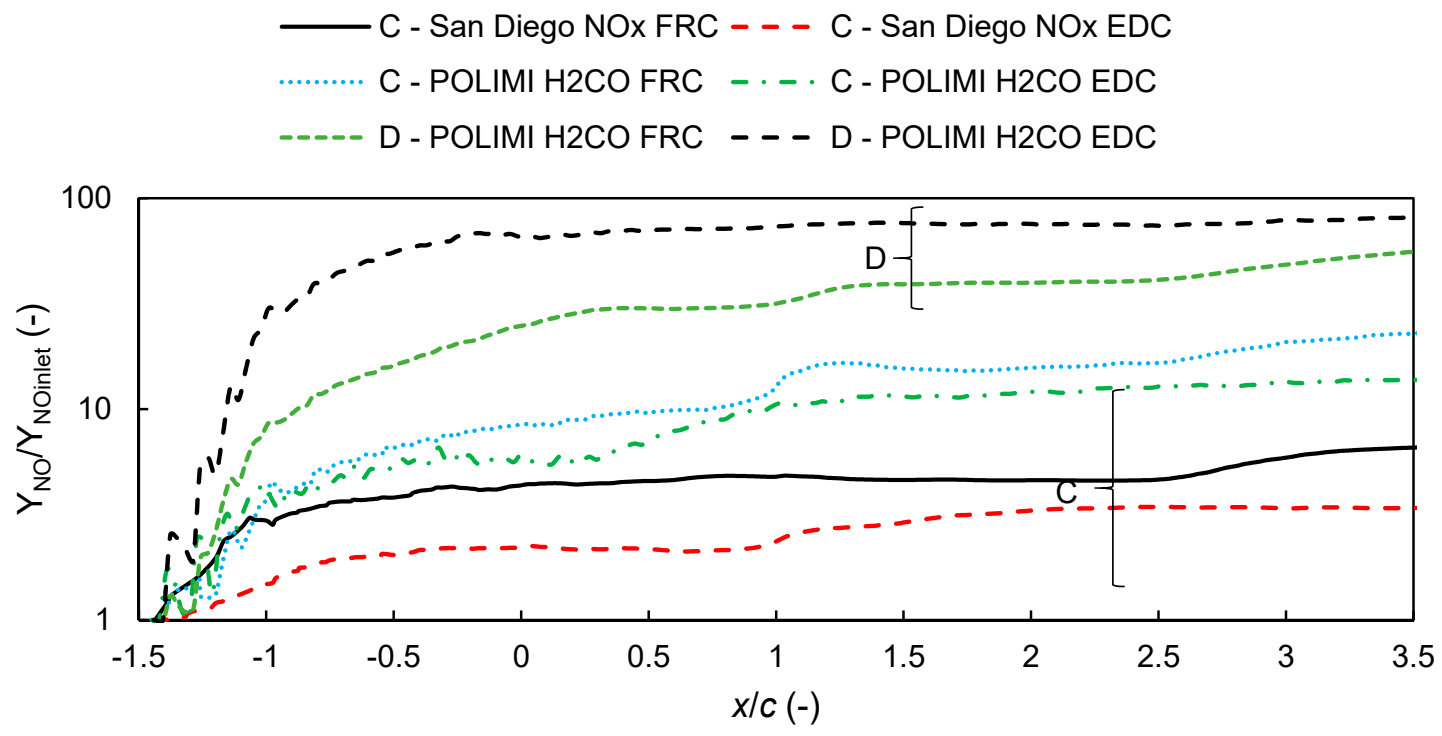

Figure 11. NO mass fractions for conditions $\mathrm{C}$ (cruise, $\mathrm{H}_{2}$ ) and $\mathrm{D}$ (cruise, $\mathrm{CH}_{4}$ ) calculated utilising the CFD model with different chemical reaction mechanisms and chemistry modelling.

The aforementioned increase seems to be related to the predicted flow field to a great extent. The NO concentration rises along the passage walls and in the wake of the blades, as shown in Figure 12. This could be a result of the increase in residence time in these regions, and the $\mathrm{NO}_{\mathrm{x}}$ emissions being influenced by the increased residence time. However, this behaviour is not expected to occur and is, most likely, an artefact of the adopted models. More specifically, the reaction rates predicted close to the passage walls are probably too high. 

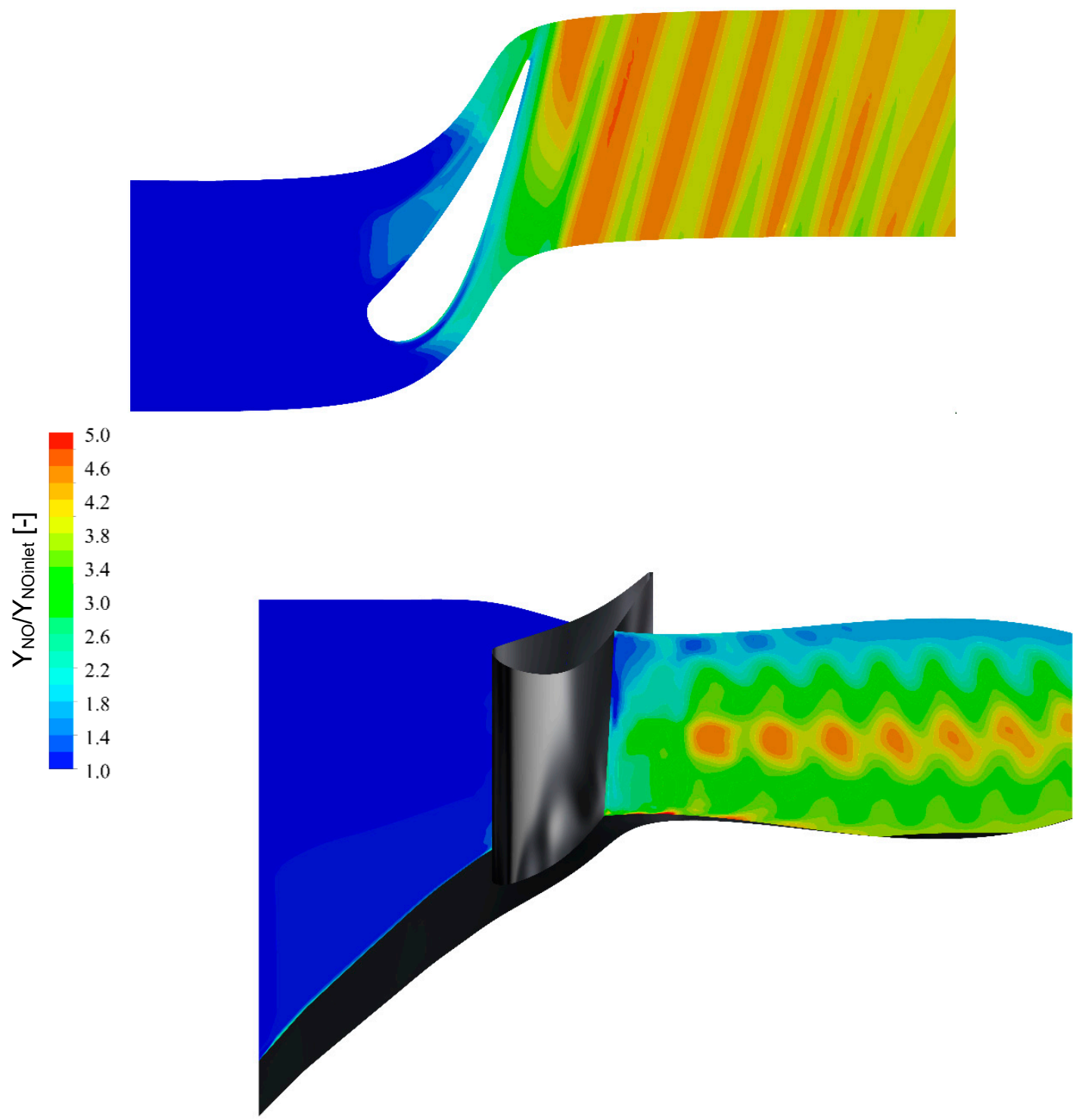

Figure 12. NO mass fraction contours non-dimensionalised by the inlet values for condition $\mathrm{C}$ with the FRC approach and the San Diego mechanism. A top view plane (above) and an axial plane (below).

The results obtained with the 1D CRN model (Figure 13) are not comparable to those of the CFD. The variations in NO mass fraction for the cruise conditions are strikingly low in the CRN calculations. The NO concentration has a slight increase from the inlet to the leading edge of the blades $(x / c<0)$, then NO drops along the blade $(0<x / c<1)$, and finally there is an inflection in the concentration at the trailing edge of the blades $(x / c>1)$. The 1D model is, as known, unable to capture the flow characteristics that seem to be driving the NO production. The difference with respect to the CFD solutions might be attributed to this fact. The high influence of the blade wakes seen for conditions $C$ and $D$ is not present for conditions $\mathrm{A}$ and $\mathrm{B}$. This can be explained by the higher operating temperature in conditions A and B. With a lower average temperature, NO formation is dependent on the local temperature variations attained within certain flow structures, while at high inlet temperatures, NO formation is largely governed by the residence time. 


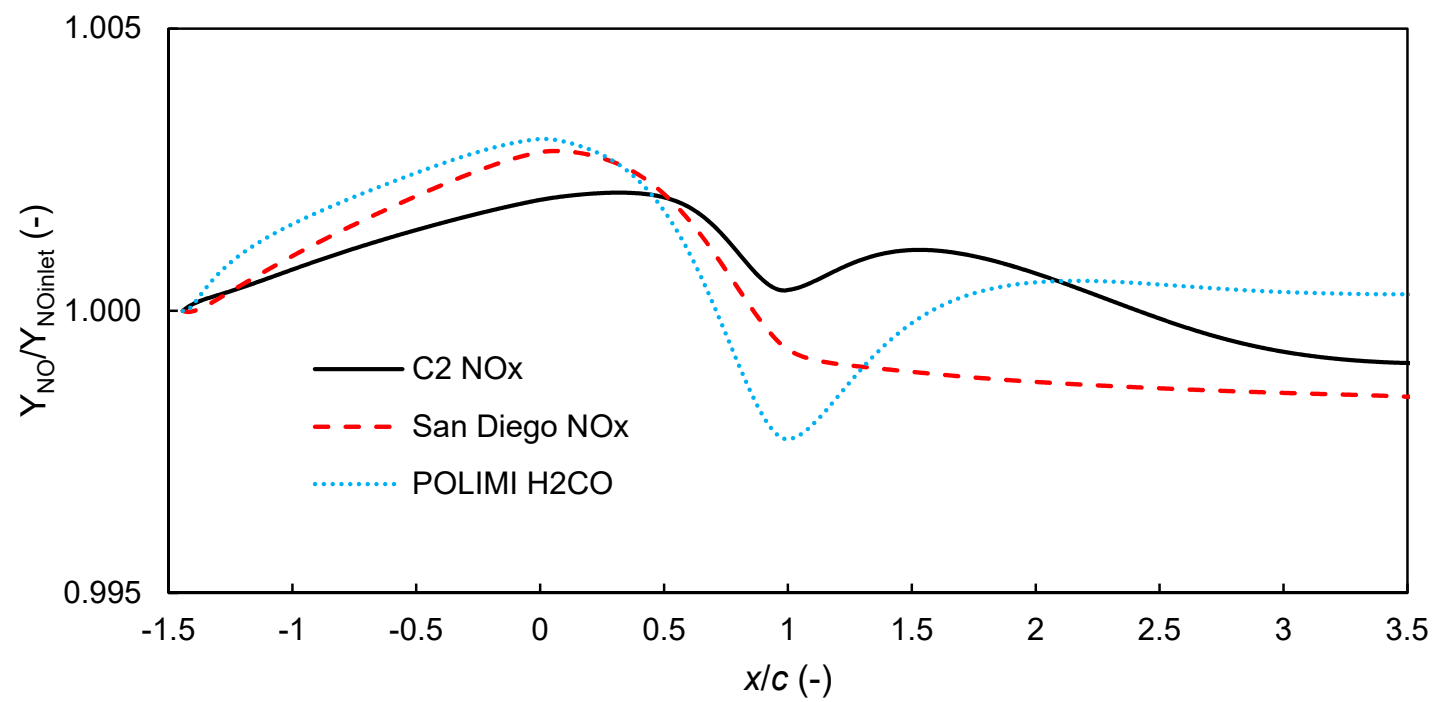

Figure 13. $\mathrm{NO}$ mass fractions for condition $\mathrm{C}$ (cruise, $\mathrm{H}_{2}$ ) calculated utilising the $\mathrm{CRN}$ model with three different chemical reaction mechanisms.

\subsection{CO Chemistry}

The behaviour of $\mathrm{CO}$ emissions is dictated by the initial composition and, to some extent, by the balance between its tendency to oxidize to $\mathrm{CO}_{2}$ and the tendency of $\mathrm{CO}_{2}$ to dissociate. It is known that dissociation is favoured at higher temperatures [35], having an exponential increase for temperatures higher than approximately $1700 \mathrm{~K}$.

The simulations of conditions A and B, as in the case of NO, show that CFD and CRN results are similar (Figure 14). The main difference between the two approaches occurs near the blade wall and in its wake. This is attributed to the lower rates of $\mathrm{CO}_{2}$ formation in the boundary layer of the blade, which is corroborated by the lower rates in condition $B$. The imposition of a constant wall temperature locally cools the fluid and reduces the rate of $\mathrm{CO}$ oxidation. A film-cooling strategy possibly has different consequences to the behaviour as the addition of air also changes the local composition. The initial drop in CO near the region in which $x / c$ is -1.5 can be attributed to the fact that the calculation of the initial composition was performed with a different chemical reaction mechanism. Like in the case of NO (Figure 9), CFD simulations had lower reaction rates than the CRN when the same chemical reaction mechanism is employed.

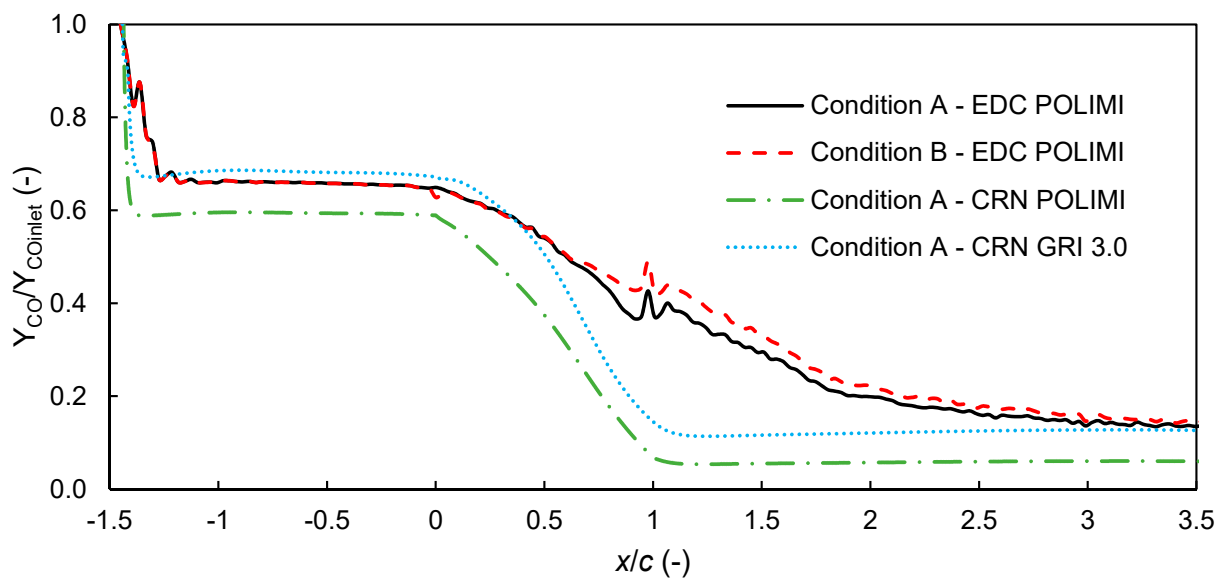

Figure 14. CO mass fractions for take-off conditions (A and B) calculated utilising the CFD model with the EDC, and the CRN model. 
The results concerning condition $\mathrm{D}$ show that $\mathrm{CO}$ undergoes an increase in concentration that starts at the leading edge of the blades in the CFD simulations (Figure 15). This behaviour is related to the increase that is predicted to occur along the blade walls, as a result of the boundary layer, as seen in Figure 16.

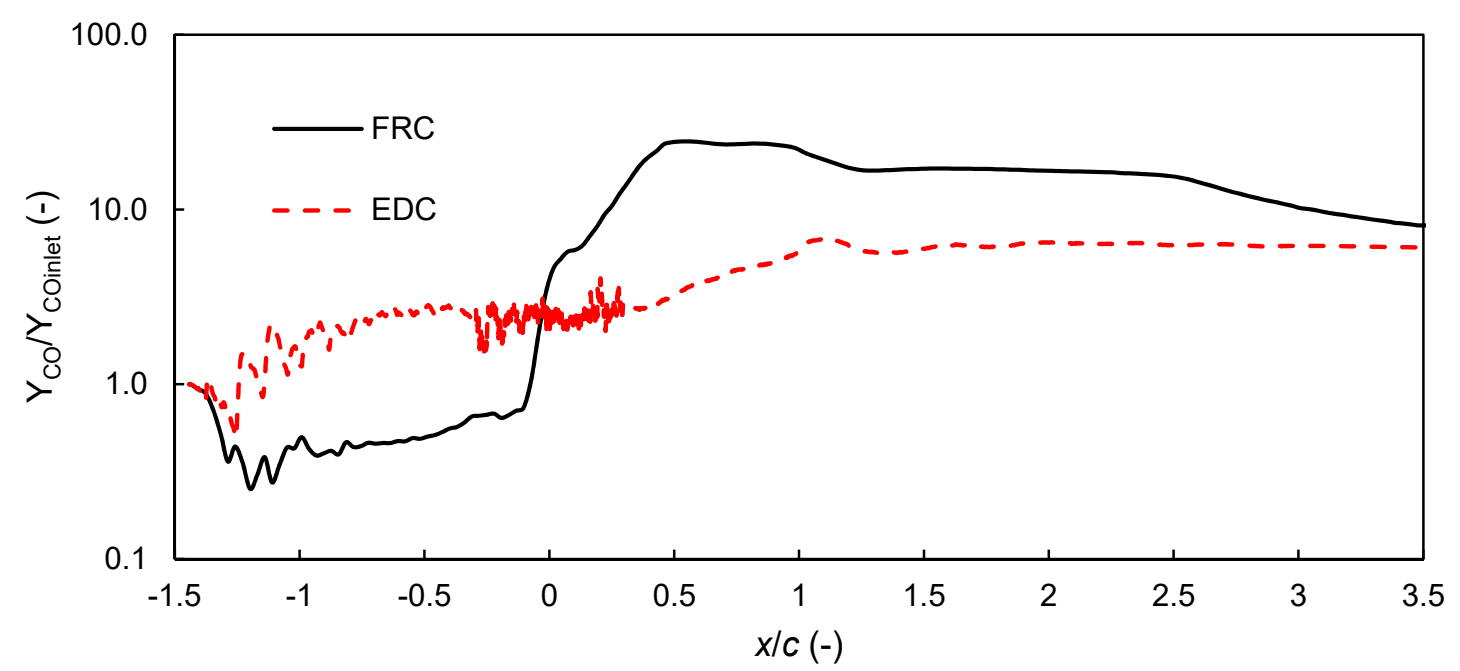

Figure 15. CO mass fractions for condition D calculated utilising the CFD model with FRC and the EDC.

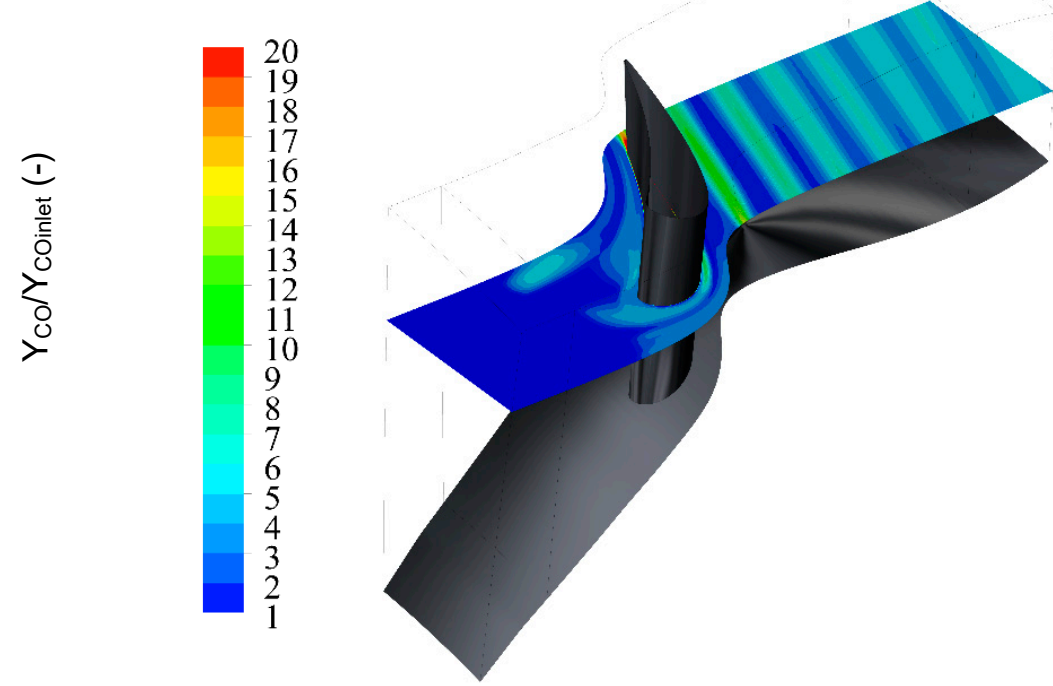

Figure 16. $\mathrm{CO}$ mass fraction non-dimensionalised by inlet concentration of $\mathrm{CO}$ for condition $\mathrm{D}$ with the EDC approach and the POLIMI $\mathrm{H}_{2} \mathrm{CO}$ mechanism. The highest values on the scale can be seen at the blade boundary layer.

The CRN results for condition $\mathrm{D}$ have completely different behaviour. The concentration drops considerably from the inlet of the stator. The behaviour does not seem to be affected by the differences in temperature or pressure along the stator. The hypothesis for the different behaviour between CFD and CRN is that, locally, the CFD simulations are able to attain conditions in which $\mathrm{CO}_{2}$ dissociation is possible, while these local conditions are not incorporated in the 1D-CRN. This hypothesis is reinforced by the analysis of the local CO concentration (Figure 16), in which most of the increase takes place along the blade walls and its wake, not modelled in the CRN. However, as for the case of NO, it is not expected that this behaviour occurs and that is most likely a shortcoming of the EDC model employed. 
While in condition $\mathrm{D}$ the $\mathrm{CFD}$ simulations predicted an increase in $\mathrm{CO}$ the prediction points to a reduction in conditions $\mathrm{A}$ and $\mathrm{B}$. This difference in the overall trend is probably due to the operating pressure since $\mathrm{CO}_{2}$ dissociation is suppressed at higher pressures.

\subsection{Overall Observations}

Another interesting result is the difference between FRC and EDC. For all investigated conditions, the EDC provided lower reaction rates, causing a lower change in species. This goes to show that neglecting turbulence-chemistry interaction may overestimate the variations in composition along the turbine.

Some of the flow structures seem to directly influence emissions. The boundary layers and near-wall flows, as well as the wakes, alter the reaction rates. This is due to different residence times and turbulence characteristics. With respect to the reactions predicted to occur close to the walls, further studies should be conducted on the adequacy of the turbulence-chemistry interaction model. It is known that the EDC model requires adjustments to this type of flow [36], which is further evidenced by the unexpected results obtained for conditions C and D. Additionally, the heat transfer to the walls and the presence of cooling should be taken into account.

\section{Conclusions and Recommendations}

This work presented computational calculations performed to model the pollutant species progression for the first stage stator of a high-pressure turbine. The changes in pollutant chemical species were monitored while using both CFD and CRN approaches, as well as different modelling approached in the CFD case.

The main conclusion of the present work is that the inclusion of the HPT stator in pollutant emission prediction is necessary for the accurate prediction of modern gas turbine emissions. Modelling approaches that do not include the HPT may under or overestimate pollutant emissions, which hinders efforts to reduce them.

The analyses also allow to draw the following conclusions:

- The inclusion of turbulence-chemistry interaction proved to be relevant, as the EDC provided lower reaction rates than a simple FRC approach. Therefore, utilising FRC may overestimate the amount of variation in the HPT.

- The discrepancy between the 1-D CRN model and the 3-D CFD model is magnified for some of the conditions. The differences seem to increase when variation in the species concentration is connected to the flow structure. At higher operating pressure and temperature, the 1-D and 3-D models had good agreement, which shows that the flow structures are not as relevant for the take-off conditions.

- The progression of $\mathrm{CO}$ along the turbine stator depends on the initial temperatures and composition as well as the local temperature maxima attained. The dissociation of $\mathrm{CO}_{2}$ may occur if the local temperatures are high enough, causing an increase in $\mathrm{CO}$. The dissociation, however, seems to be suppressed at a higher operating pressure. Further investigation in the behaviour of CO for HPT relevant conditions is advised.

Future works on the subject should consider the following recommendations:

- The precision of the chemistry solver implemented in CFD is a concern for this type of calculations. Small convergence tolerances must be imposed in order to achieve consistent solutions, which increases the required computational resources.

- Introducing wall cooling in the form of imposing a constant wall temperature slightly altered the results. It is recommended to further investigate the effect of cooling by taking into account the injection of air for creating film-cooling over the stator vanes.

- Including non-uniform inlet compositions and properties may cause different results and should be investigated. The adopted inlet boundary conditions were uniform, while in reality, a certain pattern factor is present. 
A.A.V.P., S.G.T., and A.G.R.; data curation, A.A.V.P., S.G.T., and A.G.R.; writing-original draft preparation, A.A.V.P.; writing-review and editing, A.A.V.P. and A.G.R.; visualization, A.A.V.P., S.G.T., and A.G.R.; supervision, A.G.R.; project administration, A.G.R.; funding acquisition, A.A.V.P. and A.G.R. All authors have read and agreed to the published version of the manuscript.

Funding: This research was funded by CNPq (National Counsel of Technological and Scientific Development-Brazil).

Institutional Review Board Statement: Not applicable.

Informed Consent Statement: Not applicable.

Data Availability Statement: Data is contained within the article.

Conflicts of Interest: The authors declare no conflict of interest.

\section{Nomenclature}

\begin{tabular}{|c|c|}
\hline \multicolumn{2}{|l|}{ Acronyms } \\
\hline AHEAD & Advanced Hybrid Engines for Aircraft Development \\
\hline CFD & Computational Fluid Dynamics \\
\hline CRN & Chemical Reactor Network \\
\hline EDC & Eddy Dissipation Concept \\
\hline FRC & Finite Rate Chemistry \\
\hline GCI & Grid Convergence Index \\
\hline GHG & Greenhouse Gases \\
\hline $\mathrm{HPT}$ & High-Pressure Turbine \\
\hline ITB & Inter-Turbine Burner \\
\hline $\mathrm{LH}_{2}$ & Liquid hydrogen \\
\hline LNG & Liquid Natural Gas \\
\hline LPT & Low-Pressure Turbine \\
\hline OPR & Overall Pressure Ratio \\
\hline PSR & Perfectly Stirred Reactor \\
\hline SST & Shear Stress Transport \\
\hline TIT & Turbine Inlet Temperature \\
\hline \multicolumn{2}{|c|}{ Latin Symbols } \\
\hline$c$ & Blade chord (m) \\
\hline$k$ & Turbulent kinetic energy $\left(\mathrm{m}^{2} / \mathrm{s}^{2}\right)$ \\
\hline$p$ & Pressure $(\mathrm{Pa})$ \\
\hline$T$ & Temperature (K) \\
\hline$x$ & Axial position $(\mathrm{m})$ \\
\hline Y & Mass fraction (-) \\
\hline$y^{+}$ & Dimensionle wall distance (-) \\
\hline \multicolumn{2}{|c|}{ Greek Symbols } \\
\hline$\eta_{V}$ & Vane efficiency (-) \\
\hline$\theta_{\lambda}$ & Length fraction of the turbulent fine scales (-) \\
\hline$\tau_{c}$ & Chemical time scale (s) \\
\hline$\tau_{t}$ & Turbulence time scale (s) \\
\hline$\gamma$ & Ratio of specific heats (-) \\
\hline$\varepsilon$ & Turbulent ssipation rate $\left(\mathrm{m}^{2} / \mathrm{s}^{3}\right)$ \\
\hline$\rho$ & Density $\left(\mathrm{kg} / \mathrm{m}^{3}\right)$ \\
\hline$v$ & Kinematic vcosity $\left(\mathrm{m}^{2} / \mathrm{s}\right)$ \\
\hline$\phi$ & Global equivalence rio (-) \\
\hline \multicolumn{2}{|l|}{ Subscripts } \\
\hline \multicolumn{2}{|l|}{$S$} \\
\hline \multicolumn{2}{|l|}{$T$} \\
\hline \multicolumn{2}{|l|}{0} \\
\hline 1 & Stator outlet \\
\hline \multicolumn{2}{|c|}{ Superscripts } \\
\hline$e q$ & Chemicaequilibrium \\
\hline$u$ & Unburnt reactants \\
\hline
\end{tabular}




\section{References}

1. Zhang, F.; Zhao, P.; Niu, M.; Maddy, J. The survey of key technologies in hydrogen energy storage. Int. J. Hydrog. Energy 2016, 41, 14535-14552. [CrossRef]

2. Amirante, R.; Cassone, E.; Distaso, E.; Tamburrano, P. Overview on recent developments in energy storage: Mechanical, electrochemical and hydrogen technologies. Energy Convers. Manag. 2017, 132, 372-387. [CrossRef]

3. Fasihi, M.; Bogdanov, D.; Breyer, C. Long-Term hydrocarbon trade options for the maghreb region and europe-renewable energy based synthetic fuels for a net zero emissions World. Sustainability 2017, 9, 306. [CrossRef]

4. Enagi, I.I.; Al-Attab, K.A.; Zainal, Z.A. Liquid biofuels utilization for gas turbines: A review. Renew. Sustain. Energy Rev. 2018, 90, 43-55. [CrossRef]

5. Gohardani, A.S.; Doulgeris, G.; Singh, R. Challenges of future aircraft propulsion: A review of distributed propulsion technology and its potential application for the all electric commercial aircraft. Prog. Aeronaut. Sci. 2011, 47, 369-391. [CrossRef]

6. Matthes, S.; Lührs, B.; Dahlmann, K.; Grewe, V.; Linke, F.; Yin, F.; Klingaman, E.; Shine, K.P. Climate-optimized trajectories and robust mitigation potential: Flying ATM4E. Aerospace 2020, 7, 156. [CrossRef]

7. Visser, W.P.; Broomhead, M.J. GSP, a generic object-oriented gas turbine simulation environment. In ASME Turbo Expo 2000: Power for Land, Sea, and Air; American Society of Mechanical Engineers: New York, NY, USA, 2020; pp. 1-8.

8. Lebedev, A.B.; Secundov, A.M.; Starik, A.M.; Titova, N.S.; Schepin, A.M. Modeling study of gas-turbine combustor emission. Proc. Combust. Inst. 2009, 32, 2941-2947. [CrossRef]

9. Lefebvre, A.H.; Ballal, D.R. Gas. Turbine Combustion: Alternative Fuels and Emissions; CRC Press: Boca Raton, FL, USA, 2010.

10. Park, J.; Nguyen, T.H.; Joung, D.; Huh, K.Y.; Lee, M.C. Prediction of NOx and CO emissions from an industrial lean-premixed gas turbine combustor using a chemical reactor network model. Energy Fuels 2013, 27, 1643-1651. [CrossRef]

11. Thoma, E.M.; Grönstedt, T.; Zhao, X. Quantifying the environmental design trades for a state-of-the-art turbofan engine. Aerospace 2020, 7, 148. [CrossRef]

12. Lukachko, S.P.; Waitz, I.A.; Miake-Lye, R.C.; Brown, R.C.; Anderson, M.R. Production of sulfate aerosol precursors in the turbine and exhaust nozzle of an aircraft engine. J. Geophys. Res. Atmos. 1998, 103, 16159-16174. [CrossRef]

13. Starik, A.M.; Savel'ev, A.M.; Titova, N.S.; Schumann, U. Modeling of sulfur gases and chemiions in aircraft engines. Aerosp. Sci. Technol. 2002, 6, 63-81. [CrossRef]

14. Moniruzzaman, C.G.; Yu, F. A OD aircraft engine emission model with detailed chemistry and soot microphysics. Combust. Flame 2012, 159, 1670-1686. [CrossRef]

15. Wey, C.C.; Anderson, B.A.; Wey, C.; Miake-Lye, R.C.; Whitefield, P.; Howard, R. Overview on the aircraft particle emissions experiment (APEX). J. Propuls. Power 2007, 23, 898-905. [CrossRef]

16. Bisson, J.; Seers, P.; Huegel, M.; Garnier, F. Numerical prediction of gaseous aerosol precursors and particles in an aircraft engine. J. Propuls. Power 2016, 32, 918-928. [CrossRef]

17. Nguyen, T.H.; Nguyen-Tri, P.; Vancassel, X.; Garnier, F. Aero-thermodynamic and chemical process interactions in an axial high-pressure turbine of aircraft engines. Int. J. Engine Res. 2018, 20, 1468087418772228. [CrossRef]

18. Yin, F.; Rao, A.G. Performance analysis of an aero engine with inter-stage turbine burner. Aeronaut. J. 2017, 121, 1605-1626. [CrossRef]

19. Yin, F.; Rao, A.G. Off-design performance of an interstage turbine burner turbofan engine. J. Eng. Gas Turbine Power 2017, 139, 082603-1-082603-8. [CrossRef]

20. Perpignan, A.A.V.; Talboom, M.G.; Levy, Y.; Rao, A.G. Emission Modeling of an Interturbine Burner Based on Flameless Combustion. Energy Fuels 2018, 32, 822-838. [CrossRef]

21. Perpignan, A.A.V.; Rao, A.G. Effects of chemical reaction mechanism and NOx formation pathways on an inter-turbine burner. Aeronaut. J. 2019, 123, 1-21. [CrossRef]

22. Rao, A.G.; Yin, F.; Van Buijtenen, J.P. A hybrid engine concept for multi-fuel blended wing body. Aircr. Eng. 2014, 86, 483-493.

23. Timko, L.P. Energy Efficient Engine High. Pressure Turbine Component Test. Performance Report; Technical Report No. NASA CR-168289; NASA Lewis Research Center: Cincinnati, OH, USA, 1984.

24. Murari, S.; Sunnam, S.; Liu, J.S. Steady state and transient CFD studies on aerodynamic performance validation of a high pressure turbine. In ASME Turbo Expo 2012: Turbine Technical Conference and Exposition; American Society of Mechanical Engineers Digital Collection: New York, NY, USA, 2012; pp. 2067-2077.

25. Zhang, Q.; Xu, H.; Wang, J.; Li, G.; Wang, L.; Wu, X.; Ma, S. Evaluation of CFD predictions using different turbulence models on a film cooled guide vane under experimental conditions. In ASME Turbo Expo 2015: Turbine Technical Conference and Exposition; American Society of Mechanical Engineers Digital Collection: New York, NY, USA, 2015.

26. Celik, I.B.; Ghia, U.; Roache, P.J.; Freitas, C.J.; Coleman, H.; Raad, P.E. Procedure for estimation and reporting of uncertainty due to discretization in CFD applications. J. Fluids Eng. 2008, 130, 7.

27. Gran, I.R.; Magnussen, B.F. A numerical study of a bluff-body stabilized diffusion flame. Part 1. Influence of turbulence modeling and boundary conditions. Combust. Sci. Technol. 1996, 119, 171-190. [CrossRef]

28. "Chemical-Kinetic Mechanisms for Combustion Applications", San Diego Mechanism web page, Mechanical and Aerospace Engineering (Combustion Research), University of California at San Diego. Available online: http://combustion.ucsd.edu (accessed on 30 June 2018). 
29. Frassoldati, A.; Faravelli, T.; Ranzi, E. A wide range modelling study of NOx formation and nitrogen chemistry in hydrogen combustion. Int. J. Hydrogen Energy 2006, 31, 2310-2328. [CrossRef]

30. Smith, G.P.; Golden, D.M.; Frenklach, M.; Moriarty, N.W.; Eiteneer, B.; Goldenberg, M.; Bowman, C.T.; Hanson, R.K.; Song, S.; Gardiner, W.C., Jr.; et al. Available online: http:/ / www.me.berkeley.edu/gri_mech/ (accessed on 30 June 2018).

31. Reaction Design. CHEMKIN Tutorials Manual CHEMKIN@Software. 10112/15112; Reaction Design: Livermore, CA, USA, 2011.

32. Yin, F. Modeling and Characteristics of a Novel Multi-Fuel Hybrid Engine for Future Aircraft. Ph.D. Thesis, Delft University of Technology, Mekelweg, The Netherlands, 2016.

33. Levy, Y.; Sherbaum, V.; Erenburg, V.; Krapp, V.; Paschereit, C.O.; Göke, S.; Reichel, T.; Grey, J. Chemical kinetics of the hybrid combustion system-Deliverable 2.1. Advanced Hybrid Engines for Aircraft Development; 2012.

34. Goodwin, D.G.; Moffat, H.K.; Speth, R.L. Cantera: An Object-Oriented Software Toolkit for Chemical Kinetics, Thermodynamics, and Transport Processes. Version 2.2.1. 2016. Available online: http:/ / www.cantera.org (accessed on 30 June 2018).

35. Glarborg, P.; Bentzen, L.L. Chemical effects of a high $\mathrm{CO}_{2}$ concentration in oxy-fuel combustion of methane. Energy Fuels 2007, 22, 291-296. [CrossRef]

36. Myhrvold, T. Combustion Modeling in Turbulent Boundary-Layer Flows. Ph.D. Thesis, Norwegian University of Science and Technology, Trondheim, Norwegian, 2003. 